\title{
Defects of steroidogenesis
}

\section{REVIEW ARTICLE}

\author{
A. Biason-Lauber1, M. Boscaro², F. Mantero3, and G. Balercia2 \\ 1University Children's Hospital, Division of Endocrinology and Diabetology, Zurich, Switzerland; 2Endocrinology, Department of \\ Internal Medicine and Applied Biotechnologies, Umberto I Hospital, School of Medicine, Polytechnic University of Marche, \\ Ancona; ${ }^{3}$ Endocrinology, Department of Medical and Surgical Sciences, University of Padua, Padua, Italy
}

\begin{abstract}
In the biosynthesis of steroid hormones the neutral lipid cholesterol, a normal constituent of lipid bilayers is transformed via a series of hydroxylation, oxidation, and reduction steps into a vast array of biologically active compounds: mineralocorticoids, glucocorticoids, and sex hormones. Glucocorticoids regulate many aspects of metabolism and immune function, whereas mineralocorticoids help maintain blood volume and control renal excretion of electrolytes. Sex hormones are essential for sex dif-
\end{abstract}

Steroid hormones are derivatives of cholesterol that are synthesized by a variety of tissues, most prominently the adrenal gland and gonads, although other tissues, such as liver, kidney, placenta, brain, and skin are also quite active. The cholesterol precursor can be synthesized within the cell from acetate, or derive from cholesterol ester stores in intracellular lipid droplets or from uptake of cholesterol-containing LDL. Lipoproteins taken up from plasma are most important when steroidogenic cells are chronically stimulated.

The basic cyclopentanoperhydrophenanthrene ring structure and carbon numbering system of all steroid hormones is depicted in Figure 1, using pregnenolone as an example. Pregnenolone is an example of what is called a "C-21 steroid" because it has 21 carbons. Similarly, a steroid such as testosterone is referred to as a " $\mathrm{C}-19$ steroid".

Biosynthesis of steroid hormones requires a battery of oxidative enzymes located in both mitochondria and endoplasmic reticulum. The rate-limiting step in this process is the transport of free cholesterol from the cytoplasm into mitochondria. Within mitochondria, cholesterol is converted to pregnenolone by an enzyme in the inner membrane called cytochrome P450 (see the Appendix) side-chain cleavage (P450scc). Pregnenolone itself is not a hormone but is the immediate precursor for the synthesis of all of the steroid hormones.

Typically, endocrinologists classify steroid hormones into 5 groups of molecules, based primarily on the receptor to which they bind:

\footnotetext{
Key-words: Congenital adrenal hyperplasia (CAH), Cytochrome P450, disorders of sex differentiation (DSD), steroidogenic enzymes, steroid hormones, steroidogenesis.

Correspondence: A. Biason-Lauber, University Children's Hospital, Division of Endocrinology and Diabetology, Steinwiesstrasse 75, CH-8032 Zurich, Switzerland.

E-mail: anna.lauber@kispi.uzh.ch

Accepted October 26, 2009

First published online February 24, 2010.
}

ferentiation in male and support reproduction. They include androgens, estrogens, and progestins. A block in the pathway of steroid biosynthesis leads to the lack of hormones downstream and accumulation of the upstream compounds that can activate other members of the steroid receptor family. This review deals with the clinical consequences of these blocks.

(J. Endocrinol. Invest. 33: 756-766, 2010)

๑2010, Editrice Kurtis

- glucocorticoids; cortisol is the major representative in humans

- mineralocorticoids; aldosterone being most prominent

- androgens such as testosterone

- estrogens, including estradiol and estrone

- progestogens (also known as progestins) such as progesterone.

The biosynthetic pathways for major representatives of these classes of steroid hormones is depicted in Figure 2. Steroid hormones bind to specific intracellular receptors which upon dimerization interact with the DNA in the nucleus. As a result, gene activity is modulated and a hormone-specific response occurs.

Defects in the receptor or the post-receptor machinery will lead for the most part to abnormalities of action of one specific hormone. Abnormalities of steroid hormone production, however, can result in more profound and complex effects. A block in the pathway of steroid biosynthesis leads to the lack of hormones downstream and accumulation of the upstream compounds that can activate other members of the steroid receptor family.

The consequences of such defects can be schematically categorized in 3 groups:

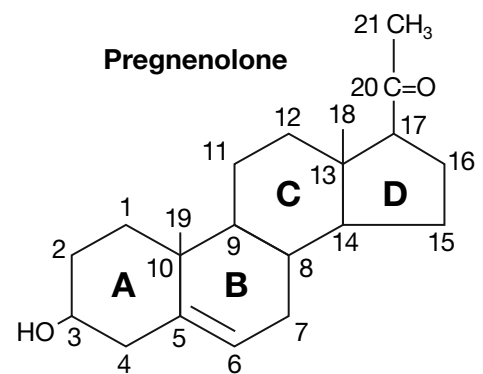

Fig. 1 - Basic cyclopentanoperhydrophenanthrene ring structure and carbon numbering system of all steroid hormones, using pregnenolone as example. 
A

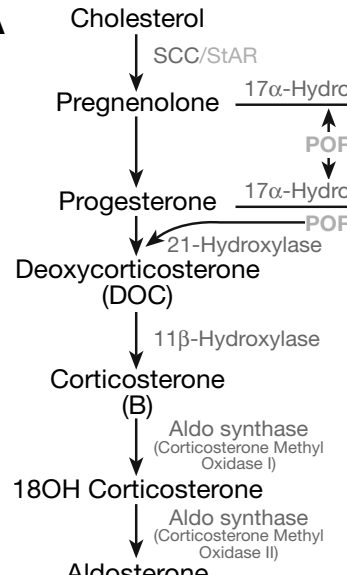

Aldosterone

B

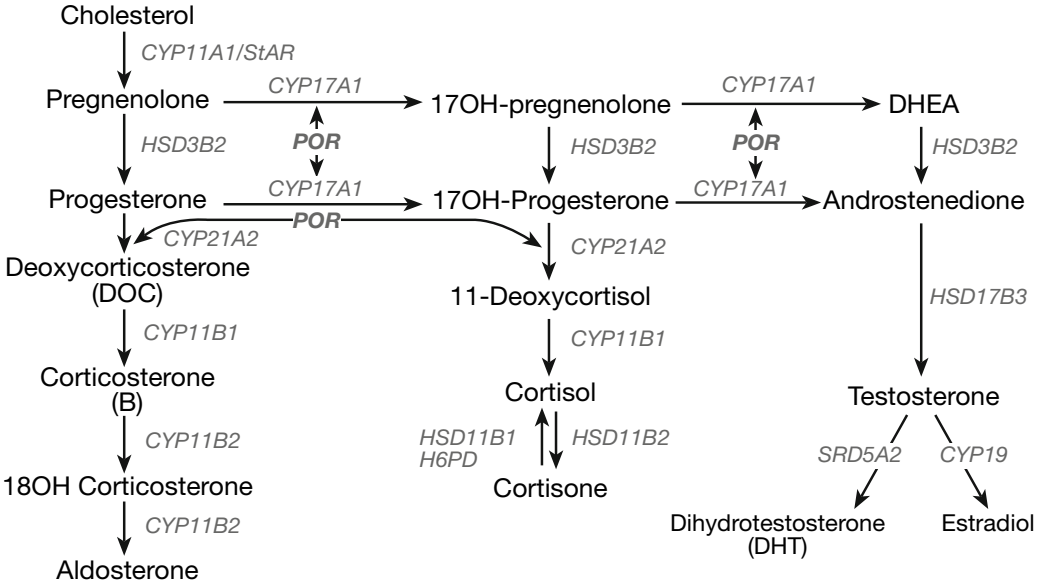

Mineralocorticoids (Salt - Water Homeostasis)
Glucocorticoids (Stress response)
Sex hormones
Fig. 2 - Steroidogenic pathway. A: Metabolites in black, P450 enzyme activities in grey, other enzyme families in light grey. $B$ : metabolites in black, genes in grey. SCC: P450 side-chain-cleavage; StAR: steroidogenic acute response protein; POR: P450 oxido reductase; HSD: hydroxysteroid dehydrogenase; H6PDH: hexose6-phosphate dehydrogenase; CYP: cytochrome P450.
1. defects leading to disorders of sex development (DSD) (1) and salt-water balance;

2. defects leading to abnormalities of salt-water balance; 3. defects leading to disorders of sex development.

Defective genes and clinical consequences of their defects are briefly summarized in Table 1.

Abnormalities of end-organ action of steroid hormones, exemplified by the hormone insensitivity syndromes can be grouped in a $4^{\text {th }}$ category.

\section{DEFECTS LEADING TO ABNORMALITIES OF SEX DEVELOPMENT AND SALT-WATER BALANCE}

The first group of steroid biosynthesis defects include the so-called congenital adrenal hyperplasia (CAH), a collective name given to a group of disorders characterized by inherited inability of the adrenals to secrete cortisol. The consequent compensatory rise of $\mathrm{ACTH}$ production causes hyperplastic growth of the adrenal glands. Blocks of the initial steps of the steroidogenic pathway impair the production of all the 3 types of steroids, causing abnormalities in the salt-water homeostasis and in sexual differentiation. That is the case in lipoid adrenal hyperplasia, where no conversion of cholesterol to any steroid takes place. This rare cause of $\mathrm{CAH}$ is characterized by salt-loss and and 46, XY DSD. In XX subjects internal and external genitalia are female, and the syndrome cannot clinically be separated from congenital adrenal hypoplasia (2). The molecular bases of such a defect have been clarified as mutations in the Steroidogenic Acute Response Protein (StAR) (3). Recently, Kim et al. screened nine 46,XY infants with adrenal failure and disordered sexual differentiation for mutations in the CYP11A1 gene encoding cytochrome P450scc and identified 2 patients, both compound heterozygotes, bringing the total number of patients with CYP11A1 mutations to 6 . Among the 6 patients, the phenotypic spectrum ranged from severe loss-of-function mutations associated with prematurity, complete underandrogenization, and severe, early-onset adrenal failure, to partial deficiencies found in children born at term with cli- 
toromegaly and later-onset adrenal failure. The authors of this work noted that, in contradistinction to congenital lipoid adrenal hyperplasia caused by StAR mutations, adrenal hyperplasia had not been reported in any of the 6 patients with P450scc deficiency (4).

\section{P450c17 (17a-hydroxylase/17,20-lyase)}

The enzyme P450c17 plays an important role in steroid production. It is essential for the synthesis of cortisol as well as the production of sex steroids. P450c17 has two distinct activities: $17 \alpha$-hydroxylase activity and 17,20lyase activity.

The ratio of the $17 \alpha$-hydroxylase to 17,20 lyase activities of human P450c17 is developmentally regulated. Adjusted for body size, the human adrenal produces nearly constant amounts of cortisol throughout life, indicating relatively constant hydroxylase activity (5). By contrast, the produc- tion of DHEA is minimal in childhood, rises 100-fold to levels that exceed the production of cortisol in young adulthood, and then gradually decreases with advancing age (6). The mechanisms by which human adrenal C19 steroid synthesis is turned on (adrenarche) and turned off (adrenopause) remain unclear. Recent clinical observations suggest a link between premature exaggerated adrenarche and the polycystic ovary syndrome (7-10).

$\mathrm{P} 450 \mathrm{c} 17$ is a single enzyme encoded by a single gene that is expressed in both the adrenals and gonads (1113). Like other microsomal P450 enzymes, P450c17 catalyzes several chemical reactions on a single active site by receiving electrons from the flavoprotein $\mathrm{P} 450$ oxidoreductase. Human P450c17 can catalyze the 17-ahydroxylation of pregnenolone to $\mathrm{OH}$-pregnenolone (170H-Preg) or of progesterone to $\mathrm{OH}$ progesterone (17OH-Prog). However, the 17,20 lyase reaction almost

Table 1 - Steroidogenesis: effect of mutation.

\begin{tabular}{|c|c|c|c|c|c|}
\hline \multirow[t]{2}{*}{ Gene } & \multirow[t]{2}{*}{ Chromosome } & \multirow[t]{2}{*}{ Molecular defect } & \multicolumn{2}{|c|}{ Sexual development } & \multirow{2}{*}{$\begin{array}{l}\text { Other organs } \\
\text { Both sexes }\end{array}$} \\
\hline & & & $X Y$ & $\mathrm{XX}$ & \\
\hline StAR & $8 p 11.2$ & LOF & $\begin{array}{l}\text { Female/ambiguous external } \\
\text { genitalia } \\
\text { Dysgenetic testes Müllerian: no }\end{array}$ & Normal & $\begin{array}{l}\text { Adrenal insufficiency } \\
\text { (lipoid adrenal hyperplasia) }\end{array}$ \\
\hline CYP11A1 & $15 q 23-q 24$ & LOF & $\begin{array}{l}\text { Ambiguous external genitalia } \\
\text { Müllerian: no }\end{array}$ & & $\begin{array}{l}\text { Adrenal insufficiency } \\
\text { w/o hyperplasia }\end{array}$ \\
\hline HSD3B2 & $1 \mathrm{p} 13.1$ & LOF & $\begin{array}{l}\text { Ambiguous/female external } \\
\text { genitalia } \\
\text { Müllerian: no }\end{array}$ & $\begin{array}{l}\text { Ambiguous external } \\
\text { genitalia }\end{array}$ & Adrenal insufficiency \\
\hline CYP21A2 & $6 p 21.3$ & LOF & Normal & $\begin{array}{l}\text { Ambiguous external } \\
\text { genitalia }\end{array}$ & Adrenal insufficiency \\
\hline CYP11B1 & $8 q 21$ & LOF & Normal & $\begin{array}{l}\text { Ambiguous external } \\
\text { genitalia }\end{array}$ & Hypertension \\
\hline \multirow[t]{2}{*}{ CYP11B2 } & $8 q 21$ & LOF & Normal & Normal & Salt loss in infancy \\
\hline & & $\begin{array}{l}\text { Unequal } \\
\text { crossing-over B1/B2 }\end{array}$ & Normal & Normal & $\begin{array}{l}\text { Glucocorticoid remediable } \\
\text { hyperaldosteronism: } \\
\text { hypertension }\end{array}$ \\
\hline CYP17A1 & $10 q 24.3$ & LOF & $\begin{array}{l}\text { Female/ambiguous external } \\
\text { genitalia } \\
\text { Normal testes } \\
\text { Müllerian: no }\end{array}$ & $\begin{array}{l}\text { Normal at birth } \\
\text { Ovarian cysts }\end{array}$ & Hypertension \\
\hline HSD17B3 & $9 q 22$ & LOF & $\begin{array}{l}\text { Ambiguous external genitalia } \\
\text { Normal testes } \\
\text { Müllerian: no } \\
\text { Gynecomastia at puberty }\end{array}$ & $\begin{array}{l}\text { Normal } \\
\text { Virilization at puberty }\end{array}$ & Normal \\
\hline CYP19 & $10 q 26.1-q 24.3$ & $\begin{array}{l}\text { LOF } \\
\text { GOF }\end{array}$ & $\begin{array}{l}\text { Normal at birth } \\
\text { No closure of growth plates } \\
\text { Heterosexual Precious } \\
\text { pseudopuberty gynecomastia }\end{array}$ & $\begin{array}{l}\text { Ambiguous genitalia } \\
\text { Progressive virilization } \\
\text { Ovarian cysts } \\
\text { Isosexual Precious } \\
\text { pseudopuberty }\end{array}$ & $\begin{array}{l}\text { Metabolic abnormalities } \\
\text { (male only) }\end{array}$ \\
\hline SRD5A2 & $2 p 23$ & LOF & $\begin{array}{l}\text { Ambiguous external genitalia } \\
\text { (perineoscrotal pseudovaginal } \\
\text { hypospadia) }\end{array}$ & Normal & Normal \\
\hline POR & $7 q^{11.2}$ & LOF & $\begin{array}{l}\text { Ambiguous genitalia } \\
\text { Müllerian : no }\end{array}$ & Ambiguous genitalia & Normal \\
\hline HSD11B1/H6PD & $1 p 36 / 1 q 32-q 41$ & LOF & Precocious pseudopuberty & $\begin{array}{l}\text { Hirsutism (adrenal } \\
\text { androgen excess) }\end{array}$ & Antley-Bixler syndrome \\
\hline HSD11B2 & $16 q 22$ & LOF & Normal & Normal & $\begin{array}{l}\text { AME: Hypertension } \\
\text { Salt retention } \\
\text { Hypokalemia } \\
\text { Normal mineralocorticoids }\end{array}$ \\
\hline
\end{tabular}

LOF: Loss-of-Function. See text for abbreviations. 

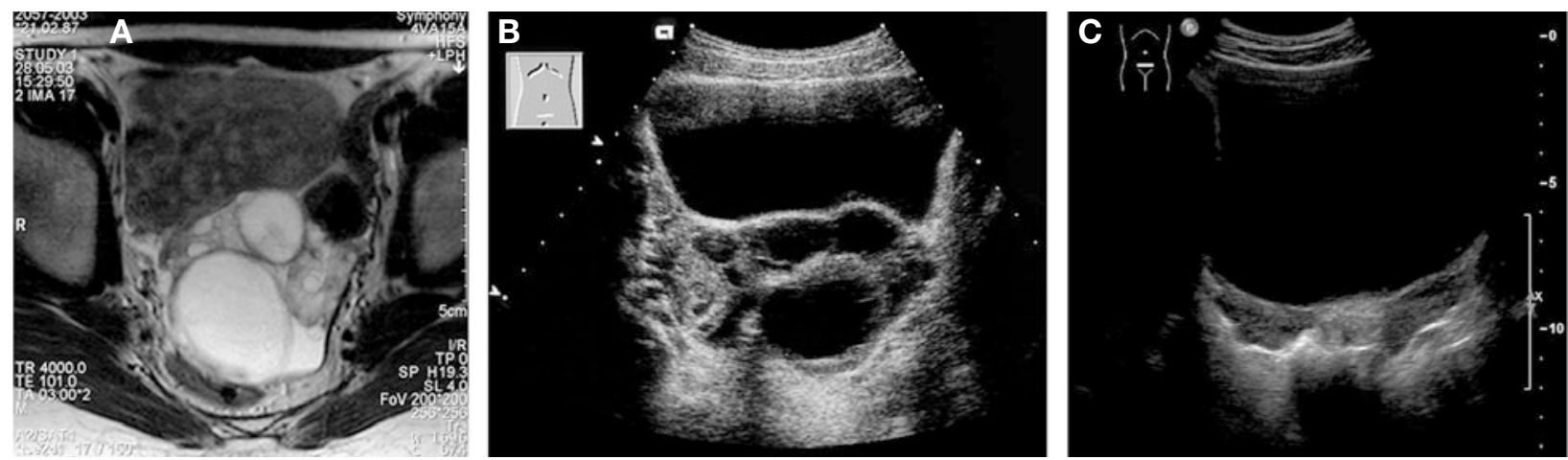

Fig. 3 - Abdominal imaging in patient 6. A) magnetic resonance imaging (MRI) at presentation (ov= ovary): hypoplastic uterus, normal vagina, ovarian masses indicated by arrows (biggest mass $4 \mathrm{~cm}$ diameter). B) Ultrasonography (US) at presentation: uterus $3.5 \times 1.4$ $\mathrm{cm}$, polycystic mass with a biggest cyst $5 \times 3.7 \mathrm{~cm}$ with a thick wall $(2-3 \mathrm{~mm})$. The ovaries are not well delimited. C: US after $15 \mathrm{months}$ of estrogen therapy $(16 \mu \mathrm{g}$ estradiol), showing reduction of the ovarian masses and signs of uterine maturation: uterus $5 \mathrm{~cm}$; right ovary $3.6 \times 3.2 \times 1.6 ; \mathrm{cm}$ left ovary $5 \times 3.6 \times 1.5 \mathrm{~cm}$; left mass $2.8 \mathrm{~cm}$ diameter.

exclusively converts $17 \mathrm{OH}$-Preg to DHEA; human P450c17 catalyzes the conversion of $17 \mathrm{OH}$-Prog to androstenedione with only $3 \%$ of the efficiency of the reaction with $17 \mathrm{OH}$-Preg (13); thus, most human sex steroids are made from DHEA. At least 3 factors influence the ratio of 17,20 lyase to $17 \alpha$-hydroxylase activities at a post-translational level. First, high molar ratios of P450 oxidoreductase to P450c17 favor lyase activity (14). Second, cytochrome $b_{5}$, an ubiquitous electron transport hemoprotein, acts allosterically to foster the interaction between $\mathrm{P} 450 \mathrm{c} 17$ and $\mathrm{P} 450$ oxidoreductase to promote the lyase reaction, but $b_{5}$ does not function as an electron donor (13-15). Third, the phosphorylation of P450c17 on serine and threonine but not tyrosine residues increases 17,20 lyase activity through as-yetunidentified mechanisms, which may involve increasing its affinity for $b_{5}$ and/or P450 oxidoreductase (16). Mutations throughout the gene have been described as leading to P450c17 deficiency. Rare cases of isolated 17,20-lyase deficiency have been reported. However, in most cases of P450c17 deficiency, both activities are reduced. Such combined 17 $\alpha$-hydroxylase/17,20-lyase-deficiency usually leads to a severe defect in the production of cortisol and sex steroids. In affected males this results in impaired masculinization with ambiguous or female external genitalia. Female patients have normal genitalia but show a lack of pubertal development in adolescence. An increased production of mineralocorticoids often leads to hypertension and hypokalemia in both sexes $(17,18)$. Therefore, P450c17 can be considered as the qualitative regulator of steroidogenesis by determining which kind of steroids will be produced (19): mineralocorticoid where $\mathrm{P} 450 \mathrm{c} 17$ is absent, glucocorticoids when $17 \alpha$-hydroxylation is active, and sex hormones when 17,20-cleavage takes place. Thus, knowledge concerning P450c17 will be of great impact for the understanding of hypertension, adrenarche, puberty, and hyperandrogenism, with obvious implications for fertility. Two main issues are confirmed by molecular, clinical and enzymatic studies of mutant P450c17: in 46, XY individuals with the complete deficiency impaired masculinization is the constant clinical hallmark of this DSD $(15,20-27)$. In $46, X X$ individuals, in whom the diagnosis seems to be infrequently made $(21,27-30)$, it is mandatory to include this rare disease in the differential diagnosis of delayed puberty in girls since a missed diagnosis can lead to severe hypertension and reproductive dysfunction (31).

Second, although P450c17 is the first hypertensive defect of steroidogenesis to be identified (17), age of onset and severity of hypertension do not seem to be as consistent. Two obvious possibilities can be considered to explain the differences in the patients' hypertension. The easiest explanation is dietary: the patients with normal blood pressure may simply be on low-salt diets. The second possibility is that the CYP17A1 some mutations are more deleterious than others. This hypothesis is consistent with model of the structure of P450c17 (32), although prediction of the precise enzymatic consequences of a mutation from any structure is not trivial. Careful examination and follow-ups of these patients might offer the chance of identifying factors influencing P450c17 activities, with possible impact in their clinical management. For instance, accurate long-term monitoring in 2 of our patients (27) suggested to us that estrogen treatment in P450c17-deficient patients might worsen the enzymatic defect, as previously implied (33). Estrogens have been previously shown to block androgen production in the gonads by inhibiting, through the estrogen receptor, expression and activity of P450c17. Since adrenal cortex also expresses $E R \alpha$, it is possible that estrogens exert the same effect in this organ. Based on an elegant study in monkeys, Wood and collaborators suggested that (exogenous) estrogens [oral contraceptives (OC) and conjugated estrogens (CEE)] divert adrenal steroidogenesis toward cortisol and away from androgen synthesis, ultimately leading to androgen-deficient hypercortisolemic state (34). This also seems to be true in humans, as demonstrated by studies in women under OC (35-37) or under post-menopause estrogen replacement therapy (3842). If cortisol cannot be synthesized, as in the case of P450c17 deficiency, the putative estrogen-driven "detour" would be further switched toward the only path- 
way that is still intact, i.e. the mineralocorticoid synthetic route. 46,XX P450c17-deficient patients often present with gonadal masses, most likely caused by acyclic hyperstimulation due to the elevated levels of gonadotropin $(27,43,44)$.

That poses a dilemma concerning the therapeutical management of 46, XX P450c17-deficient patients. In fact, these patients need estrogens to induce development of secondary sexual characteristics (as 46, XY patients do) and to maintain bone density but also to suppress gonadotropin levels, responsible for ovarian hyperstimulation and endometrial dysfunction. In some patients, however, estrogens might aggravate hypertension. As alternative, GnRH agonist in combination with lower doses of estrogens might be used to suppress gonadotropin, induce puberty and maintain female phenotype. The control of blood pressure can be initially achieved by salt restriction, although mineralocorticoid antagonists might be necessary later in life.

Cytochrome $b_{5}$ deficiency causes primarily methemoglobinemia type IV (45). One of the affected patients exhibited female genitalia at birth and was subsequently determined to be a 46 XY, DSD (46), likely because of defective P450c17 activity, which is dependent form CYB5.

Male patients affected by $\mathrm{CAH}$ due to $3 \beta$-hydroxysteroid dehydrogenase deficiency display incomplete pre-natal masculinization due to the impaired synthesis of bioactive androgens, and salt-loss due to lack of mineralocorticoid $(47,48)$. XX subjects have normal female external genitalia or mild virilization due to the action of the weak androgen DHEA.

21-hydroxylase deficiency accounts for most cases of $\mathrm{CAH}(80-90 \%$, depending on the ethnic group) $(49,50)$. Clinical consequences of 21-hydroxylase deficiency arise from overproduction of androgens.

The clinical presentation of patients with $\mathrm{CAH}$ is heterogeneous and depends on the type of gene mutation as well as on the sex of the patient (51). Some newborns with $\mathrm{CAH}$ may thus present without clinical signs or symptoms post-natally and in these the diagnosis of CAH can obviously not be made on clinical basis. The unrecognized and thus untreated disease may entail life-threatening salt-wasting crisis in the newborn period and lead to morbidity later in life, including precocious puberty and short stature. Thus, the benefit of a neonatal screening that fulfils the criteria proposed for feasibility for neonatal screening and that can prevent delayed diagnosis of $\mathrm{CAH}$ and its associated morbidity and mortality is evident $(52,53)$.

Steroid 21-hydroxylase (CYP21, also termed CYP21A2 and P450c21) is a cytochrome P-450 enzyme located in the endoplasmic reticulum. It catalyzes the conversion of 17-hydroxyprogesterone to 11-deoxycortisol, a precursor of cortisol, and the conversion of progesterone to deoxycorticosterone, a precursor of aldosterone (Fig. 2).

Patients with 21-hydroxylase deficiency cannot synthesize cortisol efficiently, and as a result, the adrenal cortex is stimulated by corticotropin and overproduces cortisol precursors. Some of these precursors are used for the biosynthesis of sex hormones, which may cause signs of androgen excess, including ambiguous genitalia in newborn girls and rapid post-natal growth in both sexes. Concomitant aldosterone deficiency may lead to salt wasting with consequent failure to thrive, hypovolemia, and shock.

\section{Clinical presentation}

Different phenotypes are observed. A severe form with a concurrent defect in aldosterone biosynthesis (salt-wasting type) and a form with apparently normal aldosterone biosynthesis (simple virilizing type) are called classic 21hydroxylase deficiency. There is also a mild, non-classic form that may be asymptomatic or associated with signs of post-natal androgen excess (54).

Classic 21-hydroxylase deficiency is detected in approximately 1 in 16,000 births in most populations (55). In Switzerland, the disease is detected in approximately $1: 10,000$ with a carrier frequency of $1: 50$, that is in agreement with figures of other European countries. The nonclassic form occurs in approximately $0.2 \%$ of the general white population but is more frequent ( 1 to $2 \%$ ) in certain populations, such as Jews of Eastern European origin (56). The lower general frequency is similar to that estimated on the basis of CYP21 genotyping of newborns in New Zealand (0.3\%) (57).

\section{Salt wasting}

Approximately $75 \%$ of patients with classic 21 -hydroxylase deficiency have severely impaired 21-hydroxylase activity and therefore cannot adequately synthesize aldosterone. Elevated levels of 21-hydroxylase substrates - mostly 17-hydroxyprogesterone - may act as mineralocorticoid antagonists, exacerbating the effects of aldosterone deficiency (58). Since aldosterone regulates sodium homeostasis, renal sodium excretion in untreated patients is excessive and can result in hypovolemia and hyperreninemia. Such patients cannot excrete potassium efficiently and are prone to hyperkalemia, especially in infancy. Cortisol deficiency in these patients contributes to poor cardiac function, poor vascular response to catecholamines, a decreased glomerular filtration rate, and increased secretion of ADH (59). Thus, cortisol and aldosterone deficiency together cause hyponatremic dehydration and shock in inadequately treated patients. Moreover, since the development of the adrenal medulla is in part dependent on glucocorticoids, patients with salt-wasting 21-hydroxylase deficiency may also have catecholamine deficiency, potentially aggravating shock (60). Patients with the salt-wasting form are identified through the measurement of serum electrolytes, aldosterone, and plasma renin and the finding of expected abnormalities hyperkalemia, low levels of aldosterone, and hyperreninemia.

\section{Ambiguous genitalia}

Girls with classic 21-hydroxylase deficiency are exposed in utero to high levels of adrenal androgens from approximately the 7 th week of gestation. Thus, such girls have ambiguous external genitalia. The uterus, fallopian tubes, and ovaries are normally formed, but there is no development of the wolffian duct. In contrast, affected boys have no overt signs of the disease except variable and subtle hyperpigmentation of the scrotum and penile enlargement. 


\section{Post-natal virilization}

In untreated or poorly treated patients, long-term exposure to high levels of sex hormones promotes rapid somatic growth and advanced skeletal age, which leads to premature epiphyseal fusion and low adult height. Pubic and axillary hair may develop early. Clitoral growth may continue in girls. Young boys may have penile growth despite having small testes, since the androgens are adrenal in origin. Long-term exposure to androgens may activate the hypothalamic-pituitary-gonadal axis, causing central precocious puberty.

\section{Reproductive function}

In girls with any form of 21-hydroxylase deficiency, signs of reproductive abnormalities, such as oligomenorrhea or amenorrhea, may develop in adolescence $(61,62)$. The issue of fertility is mainly related to psychosocial adjustment. Women with classic salt-wasting or simple virilizing disease who were born and treated in the early days tend to avoid heterosexual relationships, especially if the surgical correction of the external genitalia was inadequate or androgen levels were constantly elevated (63). As surgical, medical, and psychological treatments have improved, more women with 21-hydroxylase deficiency have successfully completed pregnancies and given birth, most by cesarean section $(64,65)$. About $80 \%$ of women with simple virilizing disease and approximately $60 \%$ of those with the severe salt-wasting form are fertile.

As compared with affected women, affected men have fewer problems with reproductive function, specifically gonadal function. Most have normal sperm counts and are able to father children $(66,67)$. One relatively common form of gonadal abnormality in affected males is the development of testicular adrenal rests, detectable by sonographic imaging before they become palpable (68). Such tumors have been detected even in childhood (69), suggesting that the search for these tumors should begin no later than adolescence. In males with salt wasting, testicular rest tissue may be accompanied by deficient spermatogenesis despite treatment. Infertility can be circumvented by intracytoplasmic sperm injection (70). These tumors are always benign and orchidectomy is usually not necessary. Proper medical treatment consists of pituitary suppression with dexamethasone, since the tumors are usually responsive to corticotropin.

Patients with simple virilizing 21-hydroxylase deficiency Patients with simple virilizing 21-hydroxylase deficiency do not synthesize cortisol efficiently, but aldosterone secretion is sufficient to maintain sodium balance. Whereas the disease is usually diagnosed in female patients shortly after birth due to genital ambiguity, the diagnosis is often delayed for several years in male patients. Without newborn screening, affected boys are usually identified when signs of androgen excess develop. Later diagnosis is associated with greater difficulty in achieving hormonal control, abnormal puberty, and short stature.

\section{Patients with non-classic disease}

Patients with non-classic 21-hydroxylase deficiency produce normal amounts of cortisol and aldosterone at the expense of mild-to-moderate overproduction of sex hormone precursors. A few non-classic cases are detected by newborn-screening programs, but most are missed because of the relatively low base-line levels of 17-hydroxyprogesterone (71-73). Hirsutism is the single most common symptom at presentation in approximately $60 \%$ of symptomatic women, followed by oligomenorrhea (54\%) and acne (33\%) (74). Thus, non-classic 21-hydroxylase deficiency and polycystic ovarian syndrome may present in similar ways.

\section{Heterozygotes}

Individuals who are heterozygous for CYP21A2 mutations often have slightly higher 17-hydroxyprogesterone levels after adrenal stimulation than unaffected subjects. Although it has been suggested that heterozygotes might be more likely to have signs of androgen excess than would genetically unaffected subjects, case-control studies do not support this concept (75).

\section{Diagnosis \\ Newborn screening}

Classic 21-hydroxylase deficiency is characterized by markedly elevated serum levels of 17-hydroxyprogesterone, the main substrate for the enzyme. Basal serum 17-hydroxyprogesterone values measured by radioimmunoassay after extraction usually exceed $300 \mathrm{nmol} / \mathrm{l}$ in infants with classical $\mathrm{CAH}$, whereas the levels in normal newborns are below $3 \mathrm{nmol} / \mathrm{l}$. This difference makes it possible to screen newborns for the disorder with the use of dried blood spots on filter paper. Screening minimizes delays in diagnosis, especially in male patients, and reduces morbidity and mortality from adrenal crises.

In recent years molecular diagnosis has been applied to confirm a diagnosis of $\mathrm{CAH}$ at the DNA level. The advantages of this method as second-tier testing rely on its high specificity.

\section{Other diagnostic procedures}

The gold standard for differentiating 21-hydroxylase deficiency from other steroidogenic enzyme defects is the corticotropin (Synachten) stimulation test, performed by injecting a $0.125-\mathrm{mg}$ or $0.25 \mathrm{-mg}$ bolus of ACTH and measuring baseline and stimulated levels of 17-hydroxyprogesterone. Blood samples are obtained at baseline and 60 min after the administration of ACTH. Except for premature infants, there are no age-related differences in the criteria for the diagnosis of 21-hydroxylase deficiency on the basis of 17-hydroxyprogesterone levels.

The severity of hormonal abnormalities depends on the type of 21-hydroxylase deficiency. Patients with salt-wasting disease have the highest 17-hydroxyprogesterone levels (up to $3000 \mathrm{nmol} / \mathrm{l}$ after corticotropin stimulation), followed by patients with simple virilizing disease, who usually have somewhat lower levels (300 to $1000 \mathrm{nmol} / \mathrm{l})$. Patients with non-classic disease have smaller elevations ( 50 to $300 \mathrm{nmol} / \mathrm{l}$ ), especially in the newborn period. Random measurements of basal serum 17-hydroxyprogesterone levels are often normal in patients with non-classic disease unless the values are obtained in the early morning. Thus, the diagnosis is most reliably made by measuring the patient's response to corticotropin stimulation. 
Other hormones whose levels are usually elevated in patients with 21-hydroxylase deficiency include progesterone, androstenedione, and to a lesser extent, testosterone. An atypical steroid, 21-deoxycortisol, is also elevated but is not routinely assayed. Mutation analysis can confirm the diagnosis and is used in some newbornscreening programs.

\section{Genetics}

Mutations in the CYP21 (CYP21A2) gene, which is located in the highly polymorphic human leucocyte antigen histocompatibility complex on chromosome 6p21.3 along with a pseudogene, CYP21A1P (CYP21P), are responsible for causing 21-hydroxylase deficiency. Although CYP21A2 and CYP21P have 98\% nucleotide-sequence identity, the latter has accumulated several mutations that totally inactivate its gene product. Most mutations causing 21-hydroxylase deficiency arise from two types of recombination between CYP21A2 and CYP21P (54).

The search for mutations is made easier since the great majority (up to 95\%) of the mutant alleles will carry 1 of the 10 pseudogene mutations. On the other hand, the high degree of sequence identity between the active gene and the pseudogene renders the specific amplification of the CYP21A2 active gene rather challenging (76).

\section{Treatment}

$\mathrm{CAH}$ is a chronic disease that requires long-term therapy. In the classical form of the disease glucocorticoids are required not only to overcome the cortisol deficiency mostly in stress situations, but also to suppress the ACTHdriven stimulation of adrenal androgens. In classical $\mathrm{CAH}$, mineralocorticoids substitution is required and salt supplementation is advisable in infancy. Surgical correction of the ambiguous genitalia in girls is also part of the management of these patients. It is not recommended to treat infant and children affected by the non-classical form of the disease until symptoms and signs of androgen excess become evident [for more details see (78)]. Steroid $11 \beta$-hydroxylase deficiency, which is responsible for $10-20 \%$ of cases of $\mathrm{CAH}$, produces symptoms of androgen excess similar to those in 21-hydroxylase deficiency. The blocked enzymatic step also results in accumulation of 11-deoxycorticosterone which has mineralocorticoid activity, leading in untreated patients to hypertension (48).

\section{DEFECTS LEADING TO ABNORMALITIES OF SALT-WATER BALANCE}

The second group of diseases includes rare abnormalities in the final step in the biosynthesis of aldosterone.

\section{Corticosterone methyl oxidase deficiency}

The CYP11B2 gene encodes a steroid 11/18- $\beta$-hydroxylase, also called aldo-synthase, that functions in mitochondria in the zona glomerulosa of the adrenal cortex to synthesize the mineralocorticoid aldosterone. The enzyme catalyzes all 3 necessary reactions: the 11- $\beta$-hydroxylation of 11-deoxycorticosterone (11-DOC) to corticosterone (B); the 18-hydroxylation of corticosterone to 18-hydroxycorticosterone (18-OHB); and the 18-oxida- tion of 18-hydroxycorticosterone to aldosterone (78). Defects in this gene can cause two clinical entities with overlapping but not identical phenotypes and different biochemical features. Corticosterone methyl oxidase (CMO) type I deficiency is an autosomal recessive disorder caused by a defect in the penultimate biochemical step of aldosterone biosynthesis, the 18-hydroxylation of corticosterone (B) to 18-hydroxycorticosterone (18-OHB). This enzymatic defect results in decreased aldosterone and salt-wasting. In CMO I deficiency, aldosterone is undetectable, whereas its immediate precursor, 18-OHB, is low or normal. These patients have an increased ratio of corticosterone to 18-OHB (79), A defect in the final step in aldosterone synthesis, the oxidation of $18-\mathrm{OHB}$ to aldosterone, results in CMO type II deficiency, in which aldosterone can be low or normal, but at the expense of increased secretion of 18-OHB. These patients have a low ratio of corticosterone to 18-OHB (79).

Although aldo-synthase/corticosterone methyl oxidase deficiency impairs the synthesis of aldosterone with consequent salt-loss in the neonatal period, some patients become completely asymptomatic later in life.

Glucocorticoid-suppressible hyperaldosteronism is an autosomal dominant disease characterized by mineralocorticoid hypertension due to an abnormal stimulatory action of $\mathrm{ACTH}$ on aldosterone synthesis. This is due to unequal crossing over between the zona glomerulosa $11 \beta$-hydroxylase (angiotensin II regulated) and the zona fasciculata 11 $\beta$-hydroxylase (ACTH regulated) genes (78). Defects in the inactivation of cortisol, such as $11 \beta$-hydroxysteroid dehydrogenase type II deficiency, can lead to hypertension with hypokalemia in absence of elevated levels of mineralocorticoids. The mechanism underlying such phenomenon is the prolonged half-life of cortisol that binds to the relatively unselective mineralocorticoid receptor in the kidney and acts like a mineralocorticoid, causing the so-called apparent mineralocorticoid excess syndrome (80). The defect of $11 \beta-$ hydroxysteroid dehydrogenase type I isoform is called cortisone reductase deficiency (CRD). CRD is a disorder in which there is a failure to regenerate the active glucocorticoid cortisol (F) from cortisone (E) via the enzyme $11 \beta$-hydroxysteroid dehydrogenase (11 $\beta$-HSD1) (81). A lack of cortisol regeneration stimulates $\mathrm{ACTH}$-mediated adrenal hyperandrogenism, with males manifesting in early life with precocious pseudopuberty and females presenting in midlife with hirsutism, oligomenorrhea, and infertility (82-87). Biochemically, CRD has been diagnosed through the assessment of urinary cortisol and cortisone metabolites and consists of measuring the tetrahydrocortisol (THF) plus 5 -THF/tetrahydrocortisone (THE) ratio (THF+5-THF/THE ratio); in CRD patients, the ratio is typically $<0.1$ (reference range 0.7-1.2) (81). $11 \beta-H S D 1$ (encoded by the HSD11B1 gene) is a bidirectional enzyme in vitro acting as a reductase (cortisone to cortisol) or as a dehydrogenase (cortisol to cortisone) but in vivo functions primarily as a reductase (81). It therefore appeared that HSD11B1 was the obvious candidate gene mutated in CRD; however, no coding mutations directly affecting enzyme activity had been identified $(82,84,86)$. The cortisol-regenerating reductase activity of $11 \beta$-HSD1 is critically dependent upon the provision of reduced 
$\mathrm{NADPH}$ in the endoplasmic reticulum lumen and is provided by the enzyme hexose-6-phosphate dehydrogenase (H6PDH, encoded by the H6PD gene). CRD has been shown to demonstrate a triallelic digenic pattern of inheritance involving mutations in the HSD11B1 and H6PD genes (83). More recently, Lavery et al. could demonstrate that CRD is caused by inactivating mutations in the H6PD gene, rendering the 11 -HSD1 enzyme unable to operate as an oxoreductase, preventing local glucocorticoid regeneration (88). These data highlight the importance of the redox control of cortisol metabolism and the 11 $\beta$-HSD1-H6PDH pathway in regulating hypothalamic-pituitary-adrenal axis activity.

\section{DEFECTS LEADING TO ABNORMALITIES OF SEXUAL DEVELOPMENT}

The third group of defects is characterized by deficiencies of enzymes responsible for the final steps of sex hormone synthesis, such as 17,20 -lyase, $17 \beta$-hydroxysteroid dehydrogenase (17 $\beta$-HSD), $5 \alpha$-reductase and aromatase. Deficient activity of 17,20 -lyase, $17 \beta-H S D$, and $5 \alpha$-reductase enzymes leads to $46, X Y$ DSD with varying genital ambiguity in $X Y$ individuals. In $X X$ individual the genitalia are generally normal. In 17,20-lyase (or 17,20desmolase) deficiency, there is no male or female pubertal development. Cortisol is normal, and there is no hypertension. The deficient enzyme is the same as in $17 \alpha$-hydroxylase deficiency and it is unknown why the defect manifests itself as $17 \alpha$-hydroxylase in some, and as 17,20 -lyase deficiency in other families. Possibly, estrogen replacement induces a conversion to $17 \alpha$-hydroxylase deficiency (89). In 17 $\beta$-HSD deficiency, there is some male pubertal development in $X Y$ individuals due to androstenedione, and often gynecomastia due to estrone. In XX individuals, there is mild virilization and insufficient development of estrogenic sexual characteristics. In $5 \alpha$-reductase deficiency, male puberty is present in $X Y$ subjects because testosterone is sufficient, and dihydrotestosterone (DHT) is not necessary for expression of male sexual secondary characteristics. In XX individuals there are no symptoms. Interestingly, at the time of expected puberty the patients affected by these deficiencies, display some degree of virilization. Particularly high is the incidence of $5 \alpha$-reductase deficiency in the Dominican Republic (90). Patients of both sexes affected by aromatase deficiency due to loss-of-function mutation in the CYP19 gene show a delayed somatic development and slower skeletal maturation, with consequent tall adult stature. Female patients affected by aromatase deficiency display various degrees of genital ambiguity, due to the lack of pre-natal exposure to estrogens, and signs of hyperandrogenism, such as acne (91). Morishima et al. (92) described a 28-yr-old XX proband and her 24-yr-old XY sib. The mother of the proband exhibited signs of progressive virilization during both pregnancies that regressed post partum. The XX proband, followed since infancy, exhibited the cardinal features of the aromatase deficiency syndrome. She had non-adrenal female pseudohermaphroditism at birth and underwent repair of the external genitalia, including a clitorectomy. At puberty, she developed progressive signs of virilization, pubertal failure with no signs of estrogen action, hypergonadotropic hypogonadism, polycystic ovaries on pelvic sonography, and tall stature. The basal concentrations of plasma testosterone, androstenedione, and 17-hydroxyprogesterone were elevated, whereas plasma estradiol was low. Hormone replacement therapy led to breast development, menses, resolution of ovarian cysts, and suppression of the elevated FSH and $\mathrm{LH}$ values. Her adult height was $177.6 \mathrm{~cm}$. Her brother was $204 \mathrm{~cm}$ tall with eunuchoid skeletal proportions. He was sexually fully mature and had macroorchidism. The bone age was $14 \mathrm{yr}$ at a chronologic age of $24 \mathrm{yr}$. Striking osteopenia was noted at the wrist and at other sites. The observations in these sibs were considered consistent with the following interpretations by the authors: a) estrogens are essential for normal skeletal maturation and proportions (but not linear growth) in men as well as in women, the accretion and maintenance of bone mineral density and mass, and the control of the rate of bone turnover; b) estrogens have a significant role in the sex steroid-gonadotropin feedback mechanism in the male, even in the face of high circulating testosterone; c) deficient estrogens in the adult male are associated with hyperinsulinemia and abnormal plasma lipids; d) placental aromatase has a critical role in protecting the female fetus from fetal masculinization and the pregnant woman from virilization. All the described case confirm these observations, although the phenotype might be variable (93-96).

By standards of other CYP genes, CYP19 is extraordinarily large (more than $50 \mathrm{~kb}$ ). The large size of the gene is probably related to the transcription of CYP19 in different cell types under the regulation of different promoters, which give rise to transcripts with unique 5-prime noncoding termini. The distal promoter (I.1) is responsible for expression uniquely in the placenta, while the proximal promoter (II), which regulates expression via a cAMPdependent signaling pathway, is responsible for expression in the gonads. Transcripts in breast adipose tissue contain 5-prime termini corresponding to expression derived from use of promoters I. 4 predominantly as well as II and I.3 [reviewed by Simpson in (97-99)].

Gain-of-function rearrangements in chromosome 15q21.2q21.3 leading to fusion of the CYP19 gene with CGNL1, TMOD3 (100) or TRPM7 (101) promoter resulting in severe estrogen excess owing to the overexpression of aromatase in many tissues cause aromatase excess syndrome. Aromatase excess syndrome is an autosomal dominant disorder characterized by increased extraglandular aromatization of steroids that presents with heterosexual precocity in males and isosexual precocity in females (102-104).

An intriguing case is that of P450 Oxidoreductase (POR) deficiency. Cytochrome P450 oxidoreductase is a flavoprotein that donates electrons to all microsomal P450 enzymes, including the steroidogenic enzymes P450c17, P450c21, and CYP51A1 (105). In 1985, a clinical report described a patient with genital ambiguity and an abnormal urinary steroid profile suggesting partial combined deficiencies of what was then thought to be 3 distinct steroidogenic enzymes: $17 \alpha$-hydroxylase, 17,20 lyase, and 21-hydroxylase (106). Affected girls are born 
with ambiguous genitalia, indicating intrauterine androgen excess. After birth, however, virilization does not progress and amounts of circulating androgens are low or normal. Conversely, affected boys are sometimes born undermasculinized. The majority but not all of patients described to date with POR deficiency also had a pattern of skeletal malformations termed Antley-Bixler syndrome. This disorder is characterized by craniosynostosis (premature fusion of bones of the skull), radioulnar or radio-humeral synostosis, bowed femora and other more variable skeletal disorders $(107,108)$. Findings of biochemical investigations of urinary steroid excretion in affected patients have shown accumulation of steroid metabolites, indicating impaired $\mathrm{C} 17$ and C21 hydroxylation, suggesting concurrent partial deficiencies of the 2 steroidogenic enzymes, P450C17 and P450C21. However, sequencing of the genes encoding these enzymes showed no mutations, which accorded with the idea of a defect in a cofactor that interacts with both enzymes. As these steroidogenic enzyme activities were known to be catalyzed by Type II cytochrome P450 enzymes, it was suggested that this patient had a disorder in the electron donor for these enzymes, P450 oxidoreductase (105). This fascinating idea remained dormant until Fluck first reported 4 cases of POR deficiency (109). Since that time, about 50 additional patients have been reported [for review see $(110,111)]$.

\section{APPENDIX}

*Cytochrome P450 (abbreviated CYP, P450, infrequently CYP450) is a very large and diverse superfamily of hemoproteins found in all domains of life $(1,2)$. Cytochromes P450 use a plethora of both exogenous and endogenous compounds as substrates in enzymatic reactions. Usually they form part of multicomponent electron transfer chains, called P450-containing systems.

The most common reaction catalyzed by cytochrome $\mathrm{P} 450$ is a monooxygenase reaction, e.g. insertion of one atom of oxygen into an organic substrate $(\mathrm{RH})$ while the other oxygen atom is reduced to water: $\mathrm{RH}+\mathrm{O}_{2}+2 \mathrm{H}^{+}+2 \mathrm{e}^{-} \rightarrow \mathrm{ROH}+\mathrm{H}_{2} \mathrm{O}$

CYP enzymes have been identified from all lineages of life, including mammals, birds, fish, insects, worms, sea squirts, sea urchins, plants, fungi, slime molds, bacteria and archaea. More than 8100 distinct CYP sequences are known (as of February 2009; see the website of the P450 Nomenclature Committee for current counts, http: //drnelson.utmem.edu /CytochromeP450.html).

The name cytochrome P450 is derived from the fact that these are colored ('chrome') cellular ('cyto') proteins, with a "pigment at $450 \mathrm{~nm}$ ", so named for the characteristic Soret peak formed by absorbance of light at wavelengths near $450 \mathrm{~nm}$ when the heme iron is reduced and complexed to carbon monoxide.

\section{REFERENCES}

1. Hughes IA, Houk C, Ahmed SF, Lee PA. Consensus statement on management of intersex disorders. Arch Dis Child 2006, 91: 554-63.

2. Prader A, Gurtner HP. Das Syndrom des Pseudohermaphroditismus masculinus bei kongenitaler Nebennierenrindenhyperplasie ohne Androgenüberproduktion. Helv Paediatr Acta 1955, 10: 397-412.

3. Lin D, Sugawara T, Strauss JF 3 rd , et al. Role of steroidogenic acute regulatory protein in adrenal and gonadal steroidogenesis. Science 1995, 267: 1828-31.

4. Kim CJ, Lin L, Huang N, et al. Severe combined adrenal and gonadal deficiency caused by novel mutations in the cholesterol side chain cleavage enzyme, P450scc. J Clin Endocrinol Metab 2008, 93: 696-702.
5. Apter D, Viinikka L, Vihko R. Hormonal pattern of adolescent menstrual cycles. J Clin Endocrinol Metab 1978, 47: 944-54.

6. Orentreich N, Brind JL, Rizer RL, Vogelman JH. Age changes and sex differences in serum dehydroepiandrosterone sulfate concentrations throughout adulthood. J Clin Endocrinol Metab 1984, 59: 551-5.

7. Oppenheimer E, Linder B, DiMartino-Nardi J. Decreased insulin sensitivity in prepubertal girls with premature adrenarche and acanthosis nigricans. J Clin Endocrinol Metab 1995, 80: 614-8.

8. Ibanez L, Potau N, Marcos MV, de Zegher F. Exaggerated adrenarche and hyperinsulinism in adolescent girls born small for gestational age. J Clin Endocrinol Metab 1999, 84: 4739-41.

9. Cutler GB Jr, Glenn M, Bush M, Hodgen GD, Graham CE, Loriaux DL. Adrenarche: a survey of rodents, domestic animals, and primates. Endocrinology 1978, 103: 2112-8.

10. Smail PJ, Faiman C, Hobson WC, Fuller GB, Winter JS. Further studies on adrenarche in nonhuman primates. Endocrinology 1982, 111: 844-8.

11. Chung BC, Picado-Leonard J, Haniu M, et al. Cytochrome P450c17 (steroid 17 alpha-hydroxylase/17,20 lyase): cloning of human adrenal and testis CDNAs indicates the same gene is expressed in both tissues. Proc Natl Acad Sci U S A 1987, 84: 407-11.

12. Picado-Leonard J, Miller WL. Cloning and sequence of the human gene for P450c17 (steroid 17 alpha-hydroxylase/17,20 lyase): similarity with the gene for P450c21. DNA 1987, 6: 439-48.

13. Auchus RJ, Lee TC, Miller WL. Cytochrome b5 augments the 17,20lyase activity of human P450c17 without direct electron transfer. J Biol Chem 1998, 273: 3158-65.

14. Nakajin S, Kobune S, Shinoda M. [Carbon monoxide inhibition of 21-hydroxylase and 17 alpha-hydroxylase activities in porcine adrenal microsomes]. Yakugaku Zasshi 1983, 103: 895-8.

15. Geller DH, Auchus RJ, Miller WL. P450c17 mutations R347H and R358Q selectively disrupt 17,20 -lyase activity by disrupting interactions with P450 oxidoreductase and cytochrome b5. Mol Endocrinol 1999, 13: 167-75.

16. Zhang LH, Rodriguez H, Ohno S, Miller WL. Serine phosphorylation of human P450c17 increases 17,20-lyase activity: implications for adrenarche and the polycystic ovary syndrome. Proc Natl Acad Sci U S A 1995, 92: 10619-23.

17. Miller WL. Steroid 17alpha-hydroxylase deficiency--not rare everywhere. J Clin Endocrinol Metab 2004, 89: 40-2.

18. Miller WL. Androgen synthesis in adrenarche. Rev Endocr Metab Disord 2009, 10: 3-17.

19. Fluck CE, Miller WL. GATA-4 and GATA-6 modulate tissue-specific transcription of the human gene for $\mathrm{P} 450 \mathrm{c} 17$ by direct interaction with Sp1. Mol Endocrinol 2004, 18: 1144-57.

20. Geller DH, Auchus RJ, Mendonca BB, Miller WL. The genetic and functional basis of isolated 17,20-lyase deficiency. Nat Genet 1997, 17: 201-5.

21. Biason-Lauber A, Kempken B, Werder E, et al. 17alpha-hydroxylase/17,20-lyase deficiency as a model to study enzymatic activity regulation: role of phosphorylation. J Clin Endocrinol Metab 2000, 85: 1226-31.

22. Biason A, Mantero F, Scaroni C, Simpson ER, Waterman MR. Deletion within the CYP17 gene together with insertion of foreign DNA is the cause of combined complete 17 alpha-hydroxylase/17,20-lyase deficiency in an Italian patient. Mol Endocrinol 1991, 5: 2037-45.

23. Biason-Lauber A, Leiberman E, Zachmann M. A single amino acid substitution in the putative redox partner-binding site of P450c17 as cause of isolated 17,20-lyase deficiency. J Clin Endocrinol Metab 1997, 82: 3807-12.

24. Biglieri EG, Herron MA, Brust N. 17-hydroxylation deficiency in man. J Clin Invest 1966, 45: 1946-54.

25. Di Cerbo A, Biason-Lauber A, Savino M, et al. Combined 17alphaHydroxylase/17,20-lyase deficiency caused by Phe93Cys mutation in the CYP17 gene. J Clin Endocrinol Metab 2002, 87: 898-905.

26. Lin D, Black SM, Nagahama Y, Miller WL. Steroid 17 alpha-hydroxylase and 17,20-lyase activities of P450c17: contributions of serine106 and P450 reductase. Endocrinology 1993, 132: 2498-506. 
27. Rosa S, Duff C, Meyer M, et al. P450c17 deficiency: clinical and molecular characterization of six patients. J Clin Endocrinol Metab 2007, 92: 1000-7.

28. Costa-Santos M, Kater CE, Auchus RJ; Brazilian Congenital Adrenal Hyperplasia Multicenter Study Group. Two prevalent CYP17 mutations and genotype-phenotype correlations in 24 Brazilian patients with 17-hydroxylase deficiency. J Clin Endocrinol Metab 2004, 89: 49-60.

29. Yanase T, Simpson ER, Waterman MR. 17 alpha-hydroxylase/17,20lyase deficiency: from clinical investigation to molecular definition. Endocr Rev 1991, 12: 91-108.

30. Martin RM, Lin CJ, Costa EM, et al. P450c17 deficiency in Brazilian patients: biochemical diagnosis through progesterone levels confirmed by CYP17 genotyping. J Clin Endocrinol Metab 2003, 88: 5739-46.

31. Taniyama $M$, Tanabe $M$, Saito $H$, Ban $Y$, Nawata $H$, Yanase $T$. Subtle 17alpha-hydroxylase/17,20-lyase deficiency with homozygous Y201N mutation in an infertile woman. J Clin Endocrinol Metab 2005, 90: 2508-11.

32. Auchus RJ, Miller WL. Molecular modeling of human P450c17 (17alpha-hydroxylase/17,20-lyase): insights into reaction mechanisms and effects of mutations. Mol Endocrinol 1999, 13: 1169-82.

33. Zachmann M, Kempken B, Manella B, Navarro E. Conversion from pure 17,20-desmolase- to combined 17,20-desmolase/17 alphahydroxylase deficiency with age. Acta Endocrinol (Copenh) 1992 127: 97-9.

34. Wood CE, Cline JM, Anthony MS, Register TC, Kaplan JR. Adrenocortical effects of oral estrogens and soy isoflavones in female monkeys. J Clin Endocrinol Metab 2004, 89: 2319-25.

35. Jung-Hoffmann C, Kuhl H. Divergent effects of two low-dose oral contraceptives on sex hormone-binding globulin and free testosterone. Am J Obstet Gynecol 1987, 156: 199-203.

36. Murphy A, Cropp CS, Smith BS, Burkman RT, Zacur HA. Effect of low-dose oral contraceptive on gonadotropins, androgens, and sex hormone binding globulin in nonhirsute women. Fertil Steril 1990, 53: 35-9.

37. Moutos D, Smith S, Zacur H. The effect of monophasic combinations of ethinyl estradiol and norethindrone on gonadotropins, androgens and sex hormone binding globulin: a randomized trial. Contraception 1995, 52: 105-9.

38. Dören M, Rübig A, Coelingh Bennink HJ, Holzgreve W. Differential effects on the androgen status of postmenopausal women treated with tibolone and continuous combined estradiol and norethindrone acetate replacement therapy. Fertil Steril 2001, 75: 554-9.

39. Tazuke S, Khaw KT, Barrett-Connor E. Exogenous estrogen and endogenous sex hormones. Medicine (Baltimore) 1992, 71: 44-51.

40. Casson PR, Elkind-Hirsch KE, Buster JE, Hornsby PJ, Carson SA, Snabes MC. Effect of postmenopausal estrogen replacement on circulating androgens. Obstet Gynecol 1997, 90: 995-8.

41. Slater CC, Zhang C, Hodis HN, et al. Comparison of estrogen and androgen levels after oral estrogen replacement therapy. J Reprod Med 2001, 46: 1052-6.

42. Kraemer RR, Synovitz LB, Gimpel T, Kraemer GR, Johnson LG, Castracane VD. Effect of estrogen on serum DHEA in younger and older women and the relationship of DHEA to adiposity and gender. Metabolism 2001, 50: 488-93.

43. ten Kate-Booij MJ, Cobbaert C, Koper JW, de Jong FH. Deficiency of 17,20-lyase causing giant ovarian cysts in a girl and a female phenotype in her 46,XY sister: case report. Hum Reprod 2004, 19: 456-9.

44. Ergun-Longmire B, Auchus R, Papari-Zareei M, Tansil S, Wilson RC, New MI. Two novel mutations found in a patient with 17alpha-hydroxylase enzyme deficiency. J Clin Endocrinol Metab 2006, 91: 4179-82.

45. Hegesh E, Hegesh J, Kaftory A. Congenital methemoglobinemia with a deficiency of cytochrome b5. N Engl J Med 1986, 314: 757-61.

46. Giordano SJ, Kaftory A, Steggles AW. A splicing mutation in the cytochrome b5 gene from a patient with congenital methemoglobinemia and pseudohermaphrodism. Hum Genet 1994, 93: 568-70.
47. Bongiovanni AM. The adrenogenital syndrome with deficiency of 3 beta-hydroxysteroid dehydrogenase. J Clin Invest 1962, 41: 2086-92.

48. New MI, White PC, Pang SA, Dupont B, Speiser PW. The adrenal hyperplasias. 6th ed. New York: McGraw-Hill, 1989.

49. Miller WL, Levine LS. Molecular and clinical advances in congenital adrenal hyperplasia. J Pediatr 1987, 111: 1-17.

50. Miller WL. Genetics, diagnosis, and management of 21-hydroxylase deficiency. J Clin Endocrinol Metab 1994, 78: 241-6.

51. Hughes IA. Congenital adrenal hyperplasia--a continuum of disorders. Lancet 1998, 352: 752-4.

52. Honour JW, Torresani T. Evaluation of neonatal screening for congenital adrenal hyperplasia. Horm Res 2001, 55: 206-11.

53. Pang S, Hotchkiss J, Drash AL, Levine LS, New MI. Microfilter paper method for 17 alpha-hydroxyprogesterone radioimmunoassay: its application for rapid screening for congenital adrenal hyperplasia. J Clin Endocrinol Metab 1977, 45: 1003-8.

54. White PC, Speiser PW. Congenital adrenal hyperplasia due to 21hydroxylase deficiency. Endocr Rev 2000, 21: 245-91.

55. Therrell BL. Newborn screening for congenital adrenal hyperplasia. Endocrinol Metab Clin North Am 2001, 30: 15-30.

56. Speiser PW, Dupont B, Rubinstein P, Piazza A, Kastelan A, New MI. High frequency of nonclassical steroid 21-hydroxylase deficiency. Am J Hum Genet 1985, 37: 650-67.

57. Fitness J, Dixit N, Webster D, et al. Genotyping of CYP21, linked chromosome $6 p$ markers, and a sex-specific gene in neonatal screening for congenital adrenal hyperplasia. J Clin Endocrinol Metab 1999, 84: 960-6.

58. Oelkers W. Adrenal insufficiency. N Engl J Med 1996, 335: 1206-12.

59. Lamberts SW, Bruining HA, de Jong FH. Corticosteroid therapy in severe illness. N Engl J Med 1997, 337: 1285-92.

60. Merke DP, Chrousos GP, Eisenhofer G, et al. Adrenomedullary dysplasia and hypofunction in patients with classic 21-hydroxylase deficiency. N Engl J Med 2000, 343: 1362-8.

61. Barnes RB, Rosenfield RL, Ehrmann DA, et al. Ovarian hyperandrogynism as a result of congenital adrenal virilizing disorders: evidence for perinatal masculinization of neuroendocrine function in women. J Clin Endocrinol Metab 1994, 79: 1328-33.

62. Deneux C, Tardy V, Dib A, et al. Phenotype-genotype correlation in 56 women with nonclassical congenital adrenal hyperplasia due to 21-hydroxylase deficiency. J Clin Endocrinol Metab 2001, 86: 207-13.

63. Mulaikal RM, Migeon CJ, Rock JA. Fertility rates in female patients with congenital adrenal hyperplasia due to 21-hydroxylase deficiency. N Engl J Med 1987, 316: 178-82.

64. Lo JC, Grumbach MM. Pregnancy outcomes in women with congenital virilizing adrenal hyperplasia. Endocrinol Metab Clin North Am 2001, 30: 207-29.

65. Premawardhana LD, Hughes IA, Read GF, Scanlon MF. Longer term outcome in females with congenital adrenal hyperplasia $(\mathrm{CAH})$ : the Cardiff experience. Clin Endocrinol (Oxf) 1997, 46: 327-32.

66. Urban MD, Lee PA, Migeon CJ. Adult height and fertility in men with congenital virilizing adrenal hyperplasia. N Engl J Med 1978, 299: 1392-6.

67. Cabrera MS, Vogiatzi MG, New MI. Long term outcome in adult males with classic congenital adrenal hyperplasia. J Clin Endocrinol Metab 2001, 86: 3070-8.

68. Stikkelbroeck NM, Otten BJ, Pasic A, et al. High prevalence of testicular adrenal rest tumors, impaired spermatogenesis, and Leydig cell failure in adolescent and adult males with congenital adrenal hyperplasia. J Clin Endocrinol Metab 2001, 86: 5721-8.

69. Murphy H, George C, de Kretser D, Judd S. Successful treatment with ICSI of infertility caused by azoospermia associated with adrenal rests in the testes: case report. Hum Reprod 2001, 16: 263-7.

70. Walker BR, Skoog SJ, Winslow BH, Canning DA, Tank ES. Testis sparing surgery for steroid unresponsive testicular tumors of the adrenogenital syndrome. J Urol 1997, 157: 1460-3. 
71. Balsamo A, Cacciari E, Piazzi S, et al. Congenital adrenal hyperplasia: neonatal mass screening compared with clinical diagnosis only in the Emilia-Romagna region of Italy, 1980-1995. Pediatrics 1996, 98: 362-7.

72. Tajima T, Fujieda K, Nakae J, et al. Molecular basis of nonclassical steroid 21-hydroxylase deficiency detected by neonatal mass screening in Japan. J Clin Endocrinol Metab 1997, 82: 2350-6.

73. Therrell BL Jr, Berenbaum SA, Manter-Kapanke $V$, et al. Results of screening 1.9 million Texas newborns for 21-hydroxylase-deficient congenital adrenal hyperplasia. Pediatrics 1998, 101: 583-90.

74. Moran C, Azziz R, Carmina E, et al. 21-Hydroxylase-deficient nonclassic adrenal hyperplasia is a progressive disorder: a multicenter study. Am J Obstet Gynecol 2000, 183: 1468-74.

75. Knochenhauer ES, Cortet-Rudelli C, Cunnigham RD, Conway-Myers BA, Dewailly D, Azziz R. Carriers of 21-hydroxylase deficiency are not at increased risk for hyperandrogenism. J Clin Endocrino Metab 1997, 82: 479-85.

76. Torresani T, Biason-Lauber A. Congenital adrenal hyperplasia: diagnostic advances. J Inherit Metab Dis 2007, 30: 563-75.

77. Clayton PE, Miller WL, Oberfield SE, Ritzén EM, Sippell WG, Speiser PW; ESPE/ LWPES CAH Working Group. Consensus statement on 21-hydroxylase deficiency from the European Society for Paediatric Endocrinology and the Lawson Wilkins Pediatric Endocrine Society. Horm Res 2002, 58: 188-95.

78. Pascoe L, Curnow KM, Slutsker L, Rosler A, White PC. Mutations in the human CYP11B2 (aldosterone synthase) gene causing corticosterone methyloxidase II deficiency. Proc Natl Acad Sci U S A 1992, 89: 4996-5000.

79. Portrat-Doyen S, Tourniaire J, Richard O, et al. Isolated aldosterone synthase deficiency caused by simultaneous E198D and V386A mutations in the CYP11B2 gene. J Clin Endocrinol Metab 1998, 83: 4156-61.

80. New MI. The prismatic case of apparent mineralocorticoid excess. $\mathrm{J}$ Clin Endocrinol Metab 1994, 79: 1-3

81. Tomlinson JW, Walker EA, Bujalska IJ, et al. 11 beta-hydroxysteroid dehydrogenase type 1: a tissue-specific regulator of glucocorticoid response. Endocr Rev 2004, 25: 831-66.

82. Biason-Lauber A, Suter SL, Shackleton CH, Zachmann M. Apparent cortisone reductase deficiency: a rare cause of hyperandrogenemia and hypercortisolism. Horm Res 2000, 53: 260-6.

83. Draper N, Walker EA, Bujalska IJ, et al. Mutations in the genes encoding 11 beta-hydroxysteroid dehydrogenase type 1 and hexose6-phosphate dehydrogenase interact to cause cortisone reductase deficiency. Nat Genet 2003, 34: 434-9.

84. Jamieson A, Wallace AM, Andrew R, et al. Apparent cortisone reductase deficiency: a functional defect in 11 beta-hydroxysteroid dehydrogenase type 1. J Clin Endocrinol Metab 1999, 84: 3570-4.

85. Malunowicz EM, Romer TE, Urban M, Bossowski A. 11 beta-hydroxysteroid dehydrogenase type 1 deficiency ('apparent cortisone reductase deficiency') in a 6-year-old boy. Horm Res 2003 59: 205-10.

86. Nikkilä H, Tannin GM, New MI, et al. Defects in the HSD11 gene encoding 11 beta-hydroxysteroid dehydrogenase are not found in patients with apparent mineralocorticoid excess or 11-oxoreductase deficiency. J Clin Endocrinol Metab 1993, 77: 687-91.

87. Phillipov G, Palermo M, Shackleton CH. Apparent cortisone reductase deficiency: a unique form of hypercortisolism. J Clin Endocrinol Metab 1996, 81: 3855-60.

88. Lavery GG, Walker EA, Tiganescu A, et al. Steroid biomarkers and genetic studies reveal inactivating mutations in hexose-6-phosphate dehydrogenase in patients with cortisone reductase deficiency. J Clin Endocrinol Metab 2008, 93: 3827-32.

89. Zachmann M, Werder EA, Prader A. Two types of male pseudohermaphroditism due to 17,20 -desmolase deficiency. J Clin Endocrinol Metab 1982, 55: 487-90.

90. Imperato-McGinley J, Gautier T, Peterson RE, Shackleton C. The prevalence of 5 alpha-reductase deficiency in children with ambiguous genitalia in the Dominican Republic. J Urol 1986, 136: 867-73.
91. Conte FA, Grumbach MM, Ito Y, Fisher CR, Simpson ER. A syndrome of female pseudohermaphrodism, hypergonadotropic hypogonadism, and multicystic ovaries associated with missense mutations in the gene encoding aromatase (P450arom). J Clin Endocrinol Metab 1994, 78: 1287-92.

92. Morishima A, Grumbach MM, Simpson ER, Fisher C, Qin K. Aromatase deficiency in male and female siblings caused by a novel mutation and the physiological role of estrogens. J Clin Endocrinol Metab 1995, 80: 3689-98.

93. Lin L, Ercan O, Raza J, et al. Variable phenotypes associated with aromatase (CYP19) insufficiency in humans. J Clin Endocrinol Metab 2007, 92: 982-90.

94. Maffei L, Murata $Y$, Rochira V, et al. Dysmetabolic syndrome in a man with a novel mutation of the aromatase gene: effects of testosterone, alendronate, and estradiol treatment. J Clin Endocrinol Metab 2004, 89: 61-70.

95. Mullis PE, Yoshimura N, Kuhlmann B, Lippuner K, Jaeger P, Harada $H$. Aromatase deficiency in a female who is compound heterozygote for two new point mutations in the P450arom gene: impact of estrogens on hypergonadotropic hypogonadism, multicystic ovaries, and bone densitometry in childhood. J Clin Endocrinol Metab 1997, 82: 1739-45.

96. Bulun SE. Aromatase deficiency in women and men: would you have predicted the phenotypes? J Clin Endocrinol Metab 1996, 81: 867-71.

97. Simpson ER. Aromatase: biologic relevance of tissue-specific expression. Semin Reprod Med 2004, 22: 11-23.

98. Simpson ER, Jones ME. Of mice and men: the many guises of estrogens. Ernst Schering Found Symp Proc 2006: 45-67.

99. Simpson ER, Michael MD, Agarwal VR, Hinshelwood MM, Bulun SE, Zhao Y. Cytochromes P450 11: expression of the CYP19 (aromatase) gene: an unusual case of alternative promoter usage. Faseb J 1997, 11: 29-36.

100. Shozu M, Sebastian S, Takayama K, et al. Estrogen excess associated with novel gain-of-function mutations affecting the aromatase gene. N Engl J Med 2003, 348: 1855-65.

101. Tiulpakov A, Kalintchenko N, Semitcheva T, et al. A potential rearrangement between CYP19 and TRPM7 genes on chromosome $15 q 21.2$ as a cause of aromatase excess syndrome. J Clin Endocrinol Metab 2005, 90: 4184-90.

102. Berkovitz GD, Guerami A, Brown TR, MacDonald PC, Migeon CJ. Familial gynecomastia with increased extraglandular aromatization of plasma carbon19-steroids. J Clin Invest 1985, 75: 1763-9.

103. Stratakis CA, Vottero A, Brodie A, et al. The aromatase excess syndrome is associated with feminization of both sexes and autosomal dominant transmission of aberrant $\mathrm{P} 450$ aromatase gene transcription. J Clin Endocrinol Metab 1998, 83: 1348-57.

104. Leiberman E, Zachmann M. Familial adrenal feminization probably due to increased steroid aromatization. Horm Res 1992, 37: 96-102.

105. Miller WL. Congenital adrenal hyperplasia. N Engl J Med 1986, 314: 1321-2

106. Peterson RE, Imperato-McGinley J, Gautier T, Shackleton C. Male pseudohermaphroditism due to multiple defects in steroid-biosynthetic microsomal mixed-function oxidases. A new variant of congenital adrenal hyperplasia. N Engl J Med 1985, 313: 1182-91.

107. Antley R, Bixler D. Trapezoidocephaly, midfacial hypoplasia and cartilage abnormalities with multiple synostoses and skeletal fractures. Birth Defects Orig Artic Ser 1975, 11: 397-401.

108. Crisponi G, Porcu C, Piu ME. Antley-Bixler syndrome: case report and review of the literature. Clin Dysmorphol 1997, 6: 61-8.

109. Fluck CE, Tajima T, Pandey AV, et al. Mutant P450 oxidoreductase causes disordered steroidogenesis with and without Antley-Bixler syndrome. Nat Genet 2004, 36: 228-30.

110. Scott RR, Miller WL. Genetic and clinical features of p450 oxidoreductase deficiency. Horm Res 2008, 69: 266-75.

111. Fluck C, Pandey A, Huang N, Agrawal V, Miller WL. P450 oxidoreductase deficiency- a new form of congenital adrenal hyperplasia. Basel: Karger, 2008 